\title{
Um Verissimo shakespeariano numa Noite de Reis
}

\author{
Luís Fernando Veríssimo, the Shakespearean, and his Twelfth Night
}

\author{
Elizabeth Ramos
}

Universidade Federal da Bahia (UFBA)

DOI: https://doi.org/10.5902/2176148564669

Resumo: Em fins do século XVI, William Shakespeare escreveu, além de outros textos dramáticos, três comédias que giram em torno da inebriante e complicada experiência de se estar apaixonado - Much ado about nothing (1598), As you like it (1599-1600) e Twelfth Night (1601). Nas três, personagens femininas ocupam papel de destaque e se tornam a força motriz da trama, superando desafios. Em 2006, a Editora Objetiva publicou o romance A décima segunda noite, do escritor, cronista, cartunista, tradutor, roteirista e dramaturgo Luís Fernando Verissimo (1936-), uma releitura bem humorada da comédia shakespeariana, Twelfth Night or What you Will. O novo texto confirma a relevância das personagens femininas da comédia inglesa e possibilita que o leitor se divirta com as identidades trocadas por meio dos disfarces de gênero. Este quinto romance do escritor gaúcho é o segundo da coleção 'Devorando Shakespeare', que pretendia publicar recriações do dramaturgo inglês. Aqui, num movimento de convergência de duas de suas paixões - a capital francesa e a produção do dramaturgo inglês - o escritor gaúcho desloca o lócus dramático da Ilíria balcânica, para a Paris dos anos 70, lócus onde se constrói o híbrido, onde se cruzam os lugares realmente vividos por diferentes sujeitos oriundos de diversos estratos sociais que se unem através do sentimento de solidariedade de grupo, próprio da condição do exílio. De maneira sensível e inteligente, o romancista insere em seu texto um narrador particular: o papagaio Henri, que constrói sua narrativa a partir do poleiro onde o colocam, no salão de cabelereiros Ilíria, de propriedade de Orsino.

Palavras-chaves: William Shakespeare. Luís Fernando Verissimo. A décima segunda noite.

Abstract: Towards the end of the sixteenth century, William Shakespeare wrote, in addition to other dramas, three comedies, which explore the inebriating and complicated experience of being in love - Much ado about nothing (1598), As you like it (1599-1600) e Twelfth Night (1601). In the three texts, female characters play leading roles, and become the driving force of the plot, overcoming challenges. In 2006, Editora Objetiva published the 
novel A décima segunda noite, by the writer, cartoonist, translator, screen play writer, and dramatist Luís Fernando Verissimo (1936-), a humorous rewriting of the Shakespearean comedy, Twelfth Night or What you Will. The new text confirms the relevance of the female characters of the English comedy, and allows the reader to enjoy the mixed identities by means of gender disguising. That fifth novel by the gaucho writer is the second one in the collection 'Devouring Shakespeare', which intended to publish recreations of the English dramatist's works. Here, in a movement of convergence of two of his passions - both the French capital and the English playwright's production - Veríssimo shifts the Illyria in the Balkans, to the city of Paris in the 1970s, where the hybrid is built, and the cross Elizabeth roads of places truly lived in by different people coming form various social backgrounds get together by means of a feeling of group solidarity proper to the condition of the exile. Sensitively and in an intelligent manner, the writer inserts in his text a particular narrator: Henry, the parrot, who builds his narrative from the perch, where he is placed, in Ilíria, a beauty saloon owned by Orsino.

Keywords: William Shakespeare. Luís Fernando Verissimo. Twelfth Night. A décima segunda noite.

A experiência que passa de pessoa a pessoa é a fonte a que recorreram todos os narradores. ${ }^{1}$ Walter Benjamin (1994, p. 198).

Em fins do século XVI, William Shakespeare, além de outras peças, escreveu três comédias que têm alguns traços em comum - Much ado about nothing (1598), As you like it (1599-1600) e Twelfth Night (1601). Nas três, os amantes se unem, depois de vencerem muitas provações e aventuras misteriosas impostas pelo destino - muitas destas associadas à inebriante e complicada experiência de se estar apaixonado. Nas três, a união se dá depois da solução de problemas gerados em face dos papéis e expectativas relacionados ao gênero das personagens. Nas três, personagens femininas ocupam papel de destaque e se tornam a força motriz da trama.

Em 2006, a Editora Objetiva publicou o romance A décima segunda noite, do escritor, cronista, cartunista, tradutor, roteirista e dramaturgo Luís Fernando Verissimo (1936-), uma releitura bem humorada da comédia shakespeariana, Twelfth Night or What you Will. O novo texto possibilita que o leitor não apenas acompanhe a trama, como também

1 BENJAMIN, Walter. O narrador: considerações sobre a obra de Nikolai Leskov. In: Magia e técnica, arte e política: ensaios sobre literatura e história da cultura. São Paulo: Brasiliense, 1994, p. 197-221. 
confirme a relevância das personagens femininas da comédia inglesa e se divirta com as identidades trocadas por meio dos disfarces de gênero que entram em cena para resolver um problema e possibilitar o final feliz, quando os amantes vencem as barreiras e comemoram a união, ingredientes que, como sabemos, são próprios da comédia shakespeariana. "Shakespeare forneceu a trama básica, e eu entrei com o resto", escreve Verissimo.

Este quinto romance do escritor gaúcho é o segundo da coleção 'Devorando Shakespeare' que pretendia publicar recriações do dramaturgo inglês. Lamentavelmente interrompida, a coleção lançou, como primeiro título, Trabalhos de amor perdidos, de Jorge Furtado, e teve como terceiro, Sonhos de uma noite de verão, de Adriana Falcão. Os três romances estabelecem profunda relação intertextual com as comédias Um Veríssimo shakespeariano numa Noite de Reis shakespearianas, num processo de transcriação que dialoga com o título da coleção e nos remete à analogia que Haroldo de Campos estabeleceu entre a tradução e a antropofagia, e deixou registrada em suas reflexões "Da razão antropofágica: diálogo e diferença na cultura brasileira":

Todo passado que nos é "outro" merece ser negado. Vale dizer: ser comido, devorado. Com esta especificação elucidativa: o canibal era um "polemista" (do grego polemos = luta, combate), mas também um "antologista": só devorava inimigos que considerava bravos, para deles tirar proteína e tutano para o robustecimento e a renovação de suas próprias forças naturais. ${ }^{2}$

Aqui, o escritor gaúcho desloca o lócus dramático da Ilíria balcânica, para a Paris dos anos 70, fazendo convergir duas de suas paixões: a capital francesa e a produção do dramaturgo inglês. O lugar a partir do qual escreve, portanto, não é simplesmente a Porto Alegre em que nasceu, nem tampouco a capital gaúcha dos dias de hoje, mas um lócus onde se constrói o híbrido, no qual se cruzam os lugares realmente vividos por diferentes sujeitos oriundos de diversos estratos sociais que se unem num "sentimento [...] de solidariedade de grupo"3, próprio da condição do exílio.

2 CAMPOS, Haroldo. Da razão antropofágica: diálogo e diferença na cultura brasileira. IN: Metalinguagem e outras metas: ensaios de teoria e crítica literária. São Paulo: Perspectiva, 1992, p. 235.

3 SAID, Edward. Reflexões sobre o exílio e outros ensaios. Trad. Pedro Maia Soares. São Paulo: Companhia das Letras, 2003, p. 51. 
Acompanhamos um enredo que se desdobra a partir do cotidiano ficcional de brasileiros procedentes de múltiplos estratos sociais, exilados por vontade própria ou por imposições político-ideológicas da época, cujas trajetórias convergem por diferentes razões. Aparecem, assim, a Negra, exilada-pioneira, que foi trabalhar como travesti no Bois de Boulogne e tornou-se, mais tarde, uma espécie de fada madrinha da comunidade brasileira, dona de uma imobiliária clandestina e do grupo de dança e música Candombleu; ou Tanira, que foi estudar Ciência Política, e terminou dona de um negócio de empadinhas; sem Elizabeth contar os perseguidos pela ditadura militar do Brasil, na época, como Ramos o pernambucano Romão. Desse modo, Veríssimo apresenta-nos um universo heterogêneo de migrações, que interagem na capital francesa dos anos 70, rompendo com as polarizações subalterno versus soberano, culto versus popular.

Claro está que sendo uma ressignificação da peça shakespeariana, ao invés de "traçar Paris", o romance desvenda com finos traços de ironia e humor, as venturas e desventuras do casal de irmãos gêmeos - Sebastião e Violeta - separados logo na alfândega do aeroporto Charles de Gaulle, quando de sua chegada à cidade. Tanto quanto William Shakespeare, Verissimo estabelece na situação de chegada a um lugar desconhecido e na separação dos irmãos o estado de descontinuidade do sujeito exilado.

\footnotetext{
O exílio [...] é fundamentalmente um estado de ser descontínuo. Os exilados estão separados das raízes, da terra natal, do passado. [...] sentem uma necessidade urgente de reconstituir suas vidas rompidas e preferem ver a si mesmos como parte de uma ideologia triunfante [...]. ${ }^{5}$
}

De maneira sensível e inteligente, o romancista insere em seu texto um narrador particular: o papagaio Henri, grande conhecedor das várias formas de narrativa e de intervenção do narrador, que constrói seu texto a partir do poleiro onde o colocam, no salão de cabelereiros

\footnotetext{
4 Construo uma relação intertextual com o livro de Verissimo, Traçando Paris, publicado pela Artes e Ofícios (1992), em que o autor elabora um mapa cultural da capital francesa, apresentando pontos e fatos que apresentam ao viajante um roteiro que vai além do mero turismo.

5 SAID, Edward. Reflexões sobre o exilio e outros ensaios. Trad. Pedro Maia Soares. São Paulo: Companhia das Letras, 2003, p. 50
} 
Ilíria. O novo romance é uma comédia, cuja trama gira em torno de Orsino, dono do salão que só contrata homens e termina se apaixonando por Olívia, uma de suas clientes. Ao contratar Cesar, sem saber que este é na verdade Violeta travestida, transforma-o em seu mensageiro junto a Olívia, que, por sua vez, se apaixona não por Violeta, mas por César. Da mesma forma, Violeta se encanta por Orsino, que estima profundamente César.

Mon Dieu, mon Dieu, um gravador. Deus dos papagaios, me acuUm Veríssimo shakespeariano da. Já ouvi minha voz gravada. Quase silenciei para sempre. É o numa Noite de som do caldeirão rachado com o qual pretendemos comover as Reis estrelas e só conseguimos fazer dançar os ursos, como escreveu Flaubert sobre a linguagem. Tente dizer qualquer coisa séria, ou profunda, com voz de papagaio. Mesmo em francês. Impossible. Foi por isso que não me deram atenção, e a comédia que vou contar quase virou tragédia. Eu avisei, me esganicei, mas me ouviram? Diziam “Le perroquet, qu'est qu'il dit?”. E riam. Eu avisando que não era comédia, era drama, era tragédia. Tinha paixão, traição, perfídia, sociologia. E riam, riam. Culpa da voz, minha sina. Com voz de papagaio, nada é importante, nada é trágico. Dizem que Shakespeare lia suas comédias com voz de papagaio para seus atores, que nunca entendiam o que ele escrevia. Só assim eles sabiam que não era tragédia. Não havia gravadores no tempo de Shakespeare. Quantos não devem sua fama póstuma ao fato de não haver um gravador por perto? 0 mundo talvez fosse outro se descobrissem que Péricles tinha a voz fina, Napoleão a língua presa e... Mas vamos à entrevista. Sei o que vocês querem ouvir. É sobre a santa que era santo, nespá? Sobre o passado. ${ }^{6}$

A escolha de um papagaio-narrador num lócus ficcional parisiense, evidentemente, estabelece uma forte relação remissiva com Gustave Flaubert (1821-1880), tornando o romance ainda mais pitoresco e estabelecendo uma segunda relação intertextual (para além da óbvia com Shakespeare) com o conto de Flaubert, Un coeur simple

6 VERISSIMO, Luís Fernando. A décima segunda noite. Coleção Devorando Shakespeare. Rio de Janeiro: Objetiva, 2006. 
(1876), em que o papagaio vai parar nas mãos de Felicité, para quem a ave passa a ser o centro das atenções. No texto do escritor francês, depois da morte do bicho, Felicité o empalha e o mantém como objeto sacralizado de decoração no seu quarto, merecedor substituto da posição da pomba sagrada ou Espírito Santo, posto que dotado do dom da fala.

Veríssimo, no entanto, vai além, e coloca em cena a arte contemporânea de narrar. Há momentos em que o narrador-papagaio se subtrai da ação narrada, e em outros fala de si, comentando sobre suas Elizabeth penas e seu estado moribundo. Na condição de mero espectador, por Ramos vezes, assume posição crítica, em outras, de narrador de experiências vividas por outros. Henri volta ao passado, não para ensinar, tal qual o 44 narrador clássico benjaminiano, mas simplesmente para contar o que viu e vivenciou, tornando-se um agenciador do entrecruzamento e do confronto entre temporalidades.

Pelo menos estão interessados no que eu tenho para contar. Só o que ouço aqui é "Le perroquet, qu'est qu'il dit?" e “Tais toi, Henri!". Fazem pouco das digressões de um caldeirão rachado. Esse é outro terror do gravador: ele não permite digressões. E o que é um papagaio sem digressões? Essa fita girando, girando, como a vida se aproximando do fim, nos obrigando a ser sucintos e breves. É contra a natureza dos papagaios serem sucintos e breves. Durante séculos, milênios, gerações e gerações, vivemos com a capacidade de falar sem saber que a tínhamos. Imaginem. Uma espécie inteira que se auto desconhecia. Imitávamos uns aos outros, imitávamos os outros bichos e os sons da floresta, mas só quando ouvimos um humano falar, pela primeira vez, descobrimos este nosso talento para articular palavras. E descobrimos o que nos faltara durante gerações e gerações de loquacidade desperdiçada e sons desconexos: assunto. Até hoje, em florestas desabitadas, papagaios selvagens voam em bandos cacofônicos sem conhecer a delícia de fazer uma frase completa, os prazeres da prosódia. É em nome deles que eu falo tanto assim. E para recuperar o tempo perdido, o nosso tempo sem assunto. Eu estaria traindo a minha ascendência se fosse sucinto e breve. Eu... Está bem, a história. Vamos a ela. Está gravando? Isso é um gravador ou uma caixa de pílulas? Ridicule. Mas vamos lá. 
Antes, alguns dados autobiográficos. Un peu de moi meme. Como cheguei ao salão Illyria. Não é digressão, é background. Como aconteceu de eu estar aqui, pintado de verde e amarelo, como parte da decoração de um salão de beleza em Paris, para ver e ouvir tudo e viver para contar o que vi e ouvi. Dois pontos. Sou descendente de um daqueles papagaios que vieram com os índios Tupinambás do Brasil para a recepção a Henri II em Rouen, no norte da França, em 1550. Quando armaram uma falsa maloca, com cinquenta Tupinambás emplumados e cinquenta franceses pintados de índio, para mostrar ao rei como era a vida na recém-descoberta Terra dos Papagaios. Nosso papel na encenação era sermos coloridos e exóticos e providenciarmos o som ambiente tropical, mas meu antepassado direto, que já tinha o meu espíri-

\section{Um Veríssimo}

shakespeariano numa Noite de Reis

7 VERISSIMO, Luís Fernando. A décima segunda noite. Coleção Devorando Shakespeare. Rio de Janeiro: Objetiva, 2006, p. 8. 
Assim, por intermédio do papagaio-narrador, diferentes tempos históricos passam a coexistir num mesmo presente: o leitor contemporâneo brasileiro lê um romance ambientado na Paris dos anos 70 e construído a partir de relações intertextuais com o século XVI de William Shakespeare. E, nessa narrativa que emerge por meio do retorno a um passado ressignificado no presente, fica estabelecido o elo com a anterioridade shakespeariana, que se faz anunciar para além do título.

Elizabeth

Ramos

[... ] o que me angustia, desde o vaudeville de palpitações em que se transformaram nossas vidas em torno do Illyria até a explosão solar que um dia transformará a Terra numa ponta de cigarro, o diverte. [...] A maior piada de todas, sustenta o Festinha, é que nossas aflições, nossas tragédias, nosso ridículo e nossa história não passam de prólogo para a explosão, que fará com o sentido da vida o mesmo que o inverno parisiense faz com a sua libido. $O$ cinzento final nos absolverá, diz Festinha. Igualará nossos gêneros e purgará todas as culpas $[. . .]^{8}$

O romancista gaúcho revela-se, então, o próprio intelectual pós-moderno de Walter Benjamim: mistura sua biblioteca pessoal com nossa história, recortes de jornal e informações disseminadas por meios de comunicação os mais diversos. Um pouco mais adiante no romance, na voz do próprio narrador: "Se vocês querem me puxar para o passado, têm que aguentar a literatura. Já que querem me ouvir, têm que aguentar a comédia disfarçada de tragédia, a tragédia disfarçada de vaudeville e esta voz de caldeirão rachado"'.

Ao ler o romance, é difícil afastar a pergunta sobre a escolha do papagaio-narrador: por que um papagaio? As respostas, que nos parecem mais plausíveis, estão relacionadas não apenas ao fato de se tratar de uma ave brasileira e de remeter a Gustave Flaubert, mas também por ser o papagaio uma ave cujo gênero não se revela facilmente, uma vez que os órgãos reprodutores são internos e, portanto, não são visíveis externamente. Resta ao observador, portanto, verificar os caracteres sexuais secundários, sendo um deles o tamanho ou a cor da plumagem,

8 VERISSIMO, Luís Fernando. A décima segunda noite. Coleção Devorando Shakespeare. Rio de Janeiro: Objetiva, 2006, p.110.

9 VERISSIMO, Luís Fernando. A décima segunda noite. Coleção Devorando Shakespeare. Rio de Janeiro: Objetiva, 2006, p. 110. 
mais colorida nos machos. Como Henri tem suas penas retocadas, sistematicamente, com tinta, a cor se torna uma característica de impedimento de constatação do gênero da ave. Assim, se identidades de gênero trocadas é um traço comum à comédia shakespeariana em tela, as possíveis reflexões que emergem na comédia Twelfth Night ficam, de certa forma, mantidas na escolha de um narrador cujo gênero é praticamente indefinido. Afinal, para os frequentadores do salão ou mesmo do apartamento, Henri não passa de um papagaio, objeto de decoração ou "o que quiserem", subtítulo da peça.

As escolhas de Verissimo fazem convergir, portanto, o rastro dramático elisabetano, as questões de gênero levantadas pela peça, o famoso papagaio de Flaubert e as reflexões do escritor francês com respeito aos tipos de narrador. É pois, Henri, o nosso papagaio-narradorUm Veríssimo shakespeariano numa Noite de Reis -personagem, que abre o texto, anunciando o fato de sua narrativa estar sendo gravada, a propósito de uma entrevista que concede a um grupo de estudantes brasileiros, a quem alerta.

Hamlet é sobre os perigos de remexer o passado, como vocês estão fazendo. Quando vocês chegaram me pedindo esta entrevista, obviamente querendo saber sobre os exilados em Paris nos anos 70 e o caso das pedras preciosas, sabem no que foi que eu pensei em seguida? No fantasma do pai do Hamlet surgindo da bruma do tempo. o fantasma que puxa Hamlet para o passado, para a reparação do passado, para a vingança, para o abismo. ${ }^{10}$

Mas desconfiado, Henri no fundo acredita que a entrevista é parte de uma investigação sobre fatos ocorridos no passado dos quais ele é testemunha: o desaparecimento de pedras preciosas que haviam sido escondidas na saia de um santo barroco, e encaminhadas a brasileiros exilados em Paris, para ajudá-los nas ações em prol da liberdade e no seu sustento.

O fato, mes amis, é que temos que por tudo num contexto. Precisamos, no mínimo, de ordem cronológica num mundo que cada vez mais desdenha a ordem. E precisamos de literatura. Vocês não veem do que estamos tratando? Está bem, de dinheiro, de

10 VERISSIMO, Luís Fernando. A décima segunda noite. Coleção Devorando Shakespeare. Rio de Janeiro: Objetiva, 2006, p. 109. 
pedras preciosas, da triste servidão humana a valores materiais que para um papagaio não significam nada. Mas também estamos tratando de outra matéria, a matéria-prima da grande literatura, a matéria de que é feita a poesia e o romance, a ironia e a tragédia: o passado. ${ }^{11}$

Assim, os eventos narrados por Henri, que também na condição de narrador-jornalista faz uso do seu direito de adicionar pitadas de ficção à narrativa, reconstroem a trama de Twelfth Night temperados com Elizabeth particularidades da sua própria história e com as inúmeras digressões, Ramos pois "é contra a natureza dos papagaios serem sucintos". Ao contrário da peça, os fatos narrados no romance de Verissimo transcorrem entre o Natal e a Noite de Reis, organizados e harmonizados de acordo com o quê e como o papagaio os vê. A duração das fitas cassete define a estrutura dos capítulos. “Agora só falta vocês me dizerem que não gravou nada e minhas palavras se perderam no ar, e minha voz lamentável esteja neste momento arranhando o domo de ozônio do planeta, tentando sair desta estufa de vaidades, rumo às estrelas. Mon Dieu, mon D."12

Com esta reclamação, encerra-se o capítulo 1, e o capítulo 2 se inicia com a pergunta "Posso continuar? Tá gravando?". Dessa forma, os capítulo do romance são configurados de acordo com cada fita.

Henri, inveterado bisbilhoteiro, pintado de verde e amarelo, dotado de cérebro pequeno, mas de excelente memória, passa os dias pousado no seu "poleiro metafórico", observando "o cortejo tragicômico da humanidade", decorando o Salão Illyria, de propriedade de Orsino, "um grande cara", embora suspeito de envolvimento com a máfia e que, a todo custo queria que o ambiente tivesse um ar brasileiro. Daí a cor das penas pintadas por Tanira, pois a cor cinza do papagaio não combinava com a decoração. "A Tanira sempre renova a [minha] pintura, mas raramente me dá banho, o que significa que já tenho camadas e camadas de verde e amarelo cobrindo minhas penas e envenenando meu organismo. [...] Serei o último dos Henris"13, uma linhagem acompanhada pelo senso trágico desde os primórdios, segundo ele.

11 VERISSIMO, Luís Fernando. A décima segunda noite. Coleção Devorando Shakespeare. Rio de Janeiro: Objetiva, 2006, p. 100.

12 VERISSIMO, Luís Fernando. A décima segunda noite. Coleção Devorando Shakespeare. Rio de Janeiro: Objetiva, 2006, p. 25.

13 VERISSIMO, Luís Fernando. A décima segunda noite. Coleção Devorando Shakespeare. Rio de Janeiro: Objetiva, 2006, p. 19. 
Claro está que, tal qual os demais personagens brasileiros instalados em Paris, Henri é construído como a metáfora do exilado.

\begin{abstract}
O exílio nos compele estranhamente a pensar sobre ele, mas é terrível de experenciar. Ele é uma fratura incurável entre um ser humano e um lugar natal, entre o eu e seu verdadeiro lar: sua tristeza essencial jamais pode ser superada. E, embora seja verdade que a literatura e a história contêm episódios heroicos, românticos, gloriosos e até triunfais da vida de um exilado, eles não são mais do que esforços para superar a dor mutiladora da separação. As realidades do exílio são permanentemente minadas pela perda de algo deixado para trás para sempre. ${ }^{14}$
\end{abstract}

Um Veríssimo shakespeariano numa Noite de Reis

Tal qual o narrador de Flaubert, Henri é também personagem, parcial e onisciente, onisciência esta derivada em boa parte do personagem Fest ou Festinha - ex-diplomata brasileiro expulso do Itamaraty após escândalo - que traz ao Illyria notícias dos acontecimentos que se dão fora dos limites do salão, em particular, no apartamento de Olívia, moradora de uma elegante cobertura no Champs de Mars.

O caráter onisciente do narrador se expande ainda, pois Henri não apenas passa o dia no Illyria, tem notícia dos acontecimentos no mundo rico de Olívia, como também participa do cotidiano do quarto e sala de Tanira. Somos todos, portanto, "reféns deste narrador" sem limites, que, por não ter umbigo, podia contrariar Flaubert para quem "o escritor deve entrar na vida real como quem entra num oceano mas só até o umbigo." 15

E é precisamente no apartamento de Tanira, jovem que mora em companhia de suas ajudantes brasileiras - Rosa (filha de um político corrupto), Margarida (ex-babá de filho de diplomata) e Hortência (ex-aspirante a atriz) - onde também Violeta irá encontrar acolhimento, trazida pela mão da Negra, a quem a recém-chegada recorre após o desaparecimento do irmão, ainda no aeroporto.

Naturalmente, mantendo o caráter dialógico com a peça shakespeariana, Violeta irá trabalhar no salão de Orsino, que con-

14 SAID, Edward. Reflexões sobre o exílio e outros ensaios. Trad. Pedro Maia Soares. São Paulo: Companhia das Letras, 2003, p. 46

15 VERISSIMO, Luís Fernando. A décima segunda noite. Coleção Devorando Shakespeare. Rio de Janeiro: Objetiva, 2006, p. 120. 
tratando apenas rapazes como cabelereiros, forçará o travestimento de Violeta em César. Dessa forma, Verissimo estende a proibição da presença de mulheres no palco elisabetano, ao salão Illyria, proibição relevada pelo narrador, quando afirma que o proprietário estava convicto de que não se tratava de "discriminação sexual porque seus rapazes representam todos os sexos conhecidos e alguns ainda em fase de experimentação." 16

Depois de muitas confusões, idas e vindas, seguindo a linha estrutural da comédia shakespeariana, o romance também terá um desfecho Elizabeth feliz com o reaparecimento de Sebastião, a divulgação da verdadeira Ramos identidade de Violeta e a consequente concretização dos amores antes proibidos: Orsino e Violeta, Olívia e Sebastião se casam.

A breve sinopse de A décima segunda noite evidencia a impossibilidade de que um significado possa ser protegido da transformação, transcendendo os contextos históricos e circunstanciais em que ocorre a leitura. É precisamente isto que observamos na construção do romance de Luis Fernando Verissimo, quando o romancista acrescenta à trama de Twelfth Night or, What you will traços do momento sociopolítico do Brasil dos anos 70 articulados por um papagaio narrador onisciente, tradução ornitológica da nacionalidade brasileira, como ironiza Roberto Pompeu de Toledo ${ }^{17}$. "Se alguém fotografasse aquela cena, Ramão no seu casulo, encurvado sobre si mesmo na poltrona triste que outros exilados lhe tinham emprestado, se lamuriando num quarto cinzento para um papagaio cinzento, teria um retrato perfeito da época"18, revela Henri referindo-se ao seu antigo proprietário, Ramão, um exilado político. Mais adiante, complementa: "Imagino que essas coisas do passado, ditaduras, exilados, traições, amores trocados, devem soar, para vocês, remotas como Shakes" ${ }^{19}$, diz Henri ao final da fita 10 que acaba antes que o narrador possa completar seu pensamento.

O escritor gaúcho apropria-se pois da segunda parcela do título - or What you will - e se liberta para fazer as suas escolhas. Lê William Shakespeare e cria um novo texto, rindo e fazendo-nos rir da tragédia

16 VERISSIMO, Luís Fernando. A décima segunda noite. Coleção Devorando Shakespeare. Rio de Janeiro: Objetiva, 2006, p. 20.

17 Papagaio! A tradução ornitológica da nacionalidade. Revista Piauí, outubro 2006.

18 VERISSIMO, Luís Fernando. A décima segunda noite. Coleção Devorando Shakespeare. Rio de Janeiro: Objetiva, 2006, p. 119.

19 VERISSIMO, Luís Fernando. A décima segunda noite. Coleção Devorando Shakespeare. Rio de Janeiro: Objetiva, 2006, p. 142. 
que desfila no palco do mundo. Tece seu romance com a trama da anterioridade, mas sem se preocupar em restituir sentidos. Suplementa o texto shakespeariano, ampliando-o por meio de acréscimos feitos sobre uma produção supostamente completa, interferindo numa suposta origem, contribuindo para que a comédia sobreviva e permaneça inevitavelmente transformada como resultado da interpretação derivada de uma cadeia de remissões, num novo original, criativo e temperado com o humor brasileiro. Não nos esqueçamos de que é o próprio papagaio Henri que assinala ao final do romance: "As criaturas se vingam dos seus criadores tendo vidas mais completas do que as deles, mesmo que trágicas". ${ }^{20} \mathrm{E}$, no final das contas, remetendo a Macbeth, comenta: "trata-se de uma história contada por um papagaio... mon Dieu, acho que é mesmo meu último suspiro! - cheia de barulho inconsequente e frivolidade, significando..." ${ }^{21}$

"O denouement, que é o nome que os franceses dão para a resolução de qualquer intriga, seja na alcova ou na guilhotina" 22 não se esgota nunca. "To-morrow, and to-morrow, and to-morrow,/Creeps in this petty pace from day to day/ To the last syllable of recorded time. ${ }^{23}$ (Macbeth, IV. v). Aqui, naturalmente, "recorded" assume caráter distinto daquele construído pelo personagem trágico, vindo dialogar com o romance do escritor gaúcho.

A fita acabou e o narrador morreu (ou seria a morte do autor disfarçado?). Quanto a Shakespeare, continua muito bem, revitalizado por meio de intérpretes que, como Luís Fernando Verissimo, possibilitam a sua sobrevivência, habilmente desatando os nós de uma trama em que aparência e realidade se confundem, mas são "encantadoramente esclarecidos" [...] "para que a ordem e a harmonia possam ser integralmente alcançadas." ${ }^{44}$

\footnotetext{
20 VERISSIMO, Luís Fernando. A décima segunda noite. Coleção Devorando Shakespeare. Rio de Janeiro: Objetiva, 2006, p. 144.

21 VERISSIMO, Luís Fernando. A décima segunda noite. Coleção Devorando Shakespeare. Rio de Janeiro: Objetiva, 2006, p. 147.

22 VERISSIMO, Luís Fernando. A décima segunda noite. Coleção Devorando Shakespeare. Rio de Janeiro: Objetiva, 2006, p. 115.

23 Minha tradução: "O amanhã, amanhã e amanhã, arrasta-se lentamente neste passo mesquinho do dia-a-dia, até a última sílaba do tempo lembrado."

24 HELIODORA, Bárbara. Comédias e romances: teatro completo. Volume 2. Rio de Janeiro: Nova Aguilar, 2009, p. 1003.
} 


\section{REFERÊNCIAS}

BENJAMIN, Walter. O narrador: considerações sobre a obra de Nikolai Leskov. In: Magia e técnica, arte e política: ensaios sobre literatura e história da cultura. São Paulo: Brasiliense, 1994, p. 197-221.

CAMPOS, Haroldo. Da razão antropofágica: diálogo e diferença na cultura brasileira. In: Metalinguagem e outras metas: ensaios de teoria e crítica literária. São Paulo: Perspectiva, 1992.

Elizabeth

Ramos

CANCLINI, Néstor Garcia. Culturas híbridas. Trad.: Ana Regina Lessa e Heloísa Pezza Cintrão. São Paulo: Edusp, 2008.

KERMODE, Frank. A linguagem de Shakespeare. Tradução de Barbara Heliodora. Rio de Janeiro: Record, 2006.

RODRIGUES, Cristina Carneiro. Tradução e diferença. São Paulo: Editora UNESP, 2000.

SAID, Edward. Reflexões sobre o exílio e outros ensaios. Trad. Pedro Maia Soares. São Paulo: Companhia das Letras, 2003.

SANTIAGO, Silviano. O narrador pós-moderno. IN: Nas malhas da letra: ensaios. Rio de Janeiro: Roco, 2002. p. 44-60

SHAKESPEARE, William. Comédias e romances: teatro completo. Volume 2. Tradução: Barbara Heliodora. Rio de Janeiro: Nova Aguilar, 2009.

SHAKESPEARE, William. Twelfth night, or What you will. IN: WELLS, Stanley; TAYLOR, Gary (ed.). The Oxford Shakespeare: the complete works. $2^{\text {nd }}$ Ed. Oxford: Oxford University Press, 2005.

TÁPIA, Marcelo. $O$ eco antropofágico: reflexões sobre a transcriação e a metáfora sanguíneo-canibalesca. In: TÁPIA, Marcelo.; NÓBREGA, Thelma Médici (Org.). Haroldo de Campos. Transcriação. São Paulo: Perspectiva, 2013, 205-232. 
TOLEDO, Roberto Pompeu. Papagaio! A tradução ornitológica da nacionalidade. Revista Piauí, outubro 2006.

VERISSIMO, Luís Fernando. A décima segunda noite. Coleção Devorando Shakespeare. Rio de Janeiro: Objetiva, 2006.

Um Veríssimo

shakespeariano

numa Noite de

Reis

53 
